\title{
О ФИЗИКО-ХИМИЧЕСКИХ ХАРАКТЕРИСТИКАХ ИЗОМЕРНЫХ Н-ДЕЦИНОВ
}

Anne ELVELT, O. EISEN. n-DETSUONIDE FUOSIKALIS-KEEMILISTEST OMADUSTEST Anne ELVELT, O. EISEN. ON PHYSICO-CHEMICAL PROPERTIES OF $n$-DECYNES

В настоящем сообщении публикуются результаты систематического исследования важнейших физико-химических свойств изомеров положения тройной связи нормальных децинов, сведения о которых в литературе $\left[{ }^{1-3}\right]$ отрывочны.

Децины синтезированы по методу Азингера, Фелла и Стефана [ $\left.{ }^{4}\right]$, очищены ректификацией и дополнительно методом препаративной газовой хроматографии. Чистота веществ по данным капиллярного газохроматографического анализа колебалась в пределах 99,3-99,8 (см. табл. 1).

Плотности $\left(d_{4}\right)$ и показатели преломления $\left(n_{D}\right)$ изомеров децинов для ряда температур измерялись по методикам, изложенным в [5] и. [ $\left.{ }^{6}\right]$ соответственно.

Температурная зависимость названных характеристик представлена в форме уравнения

$$
g^{t}=g^{20}+\alpha(t-20)+\beta(t-20)^{2},
$$

где $g=d_{4}, n_{D}$, константы которого, определенные методом наименьших квадратов, приведены в табл. 1 вместе со значениями плотностей и показателей преломления для температуры $20^{\circ} \mathrm{C}$. На основе полученных экспериментальных данных для каждого изомера рассчитаны молекулярная рефракция $\left(R_{D}\right)$ и интерцепт рефракции $(r)$ при $20^{\circ}$ (см. табл. 1).

Таблица 2

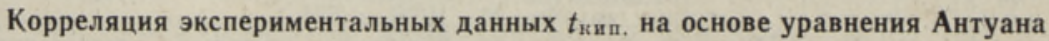

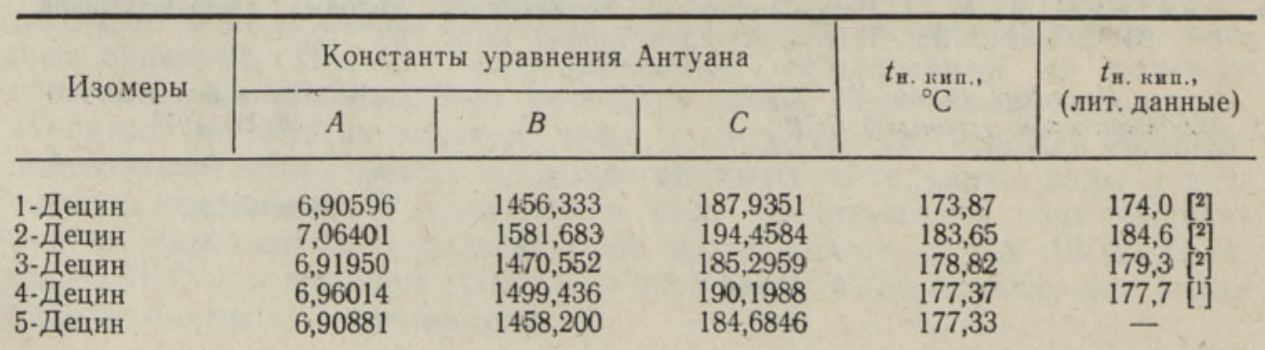


ปั้

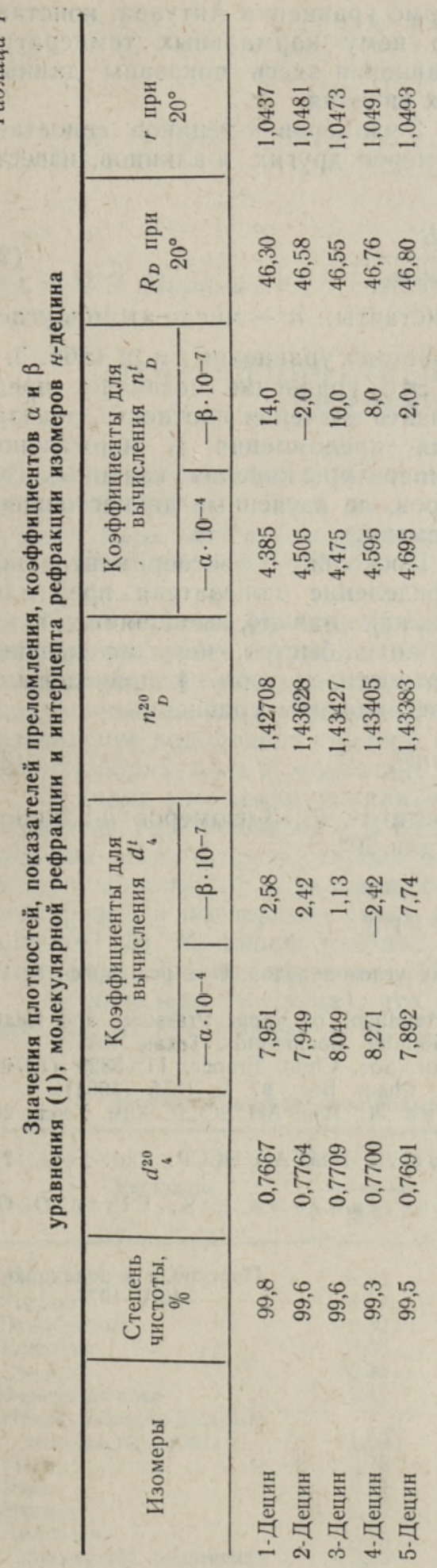

๑

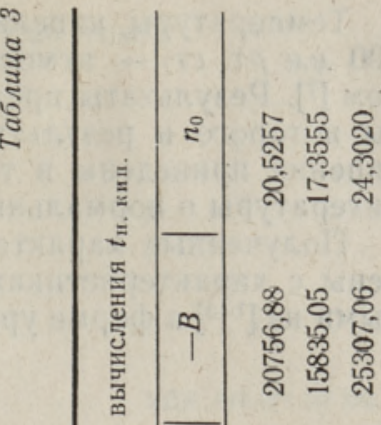

ลิ

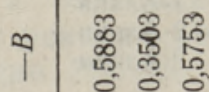

$=$



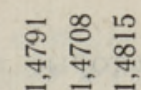

늘 귱

क्षิ- -50

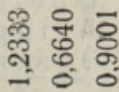

\begin{tabular}{lll}
$\infty$ & \multirow{1}{*}{} \\
ஸे \\
$\infty$ & $\infty$ & 0 \\
0 & 0 & 0
\end{tabular}

:

重章 
Температуры кипения названных изомеров в интервале давлений 200 м. рт. ст. - атмосферное определялись эбуллиометрическим методом [7]. Результаты представлены в форме уравнения Антуана, константы которого и результаты расчета по нему нормальных температур кипения приведены в табл. 2. Для сравнения здесь показаны данные литературы о нормальных температурах кипения.

Полученные характеристики 1-, 2-, 3-изомеров лены с характеристиками этих же изомеров других $H$-алкинов, известными из $\left[{ }^{1-3}\right]$ в форме уравнения

$$
g=A+\frac{B}{n_{0}+n},
$$

где $g=d_{4}^{20}, n_{D}^{20}, \quad t_{\text {нтк }} ; A, B, n_{0}$ - константы; $n$-число атомов углерода в молекуле изомера. Значения констант уравнения см. в табл. 3.

Это уравнение позволяет предтаблица 4 сказать значения плотности, показателя преломления и нормальной температуры кипения указанных изо-

Коэффициенты $a, b$ уравнения (3)

\begin{tabular}{c|c|c}
\hline Изомеры & $-a$ & $b$ \\
\hline 1-Алкин & 1,6993 & 1,7271 \\
2-Алкин & 2,4390 & 2,2414 \\
3-Алкин & 2,3679 & 2,1893
\end{tabular}
меров, не изученные до настоящего времени.

Поскольку экспериментальнос определение показателя преломления, как правило, выполняется более точно и быстро, чем определение плотности, в табл. 4 приведены и коэффициенты уравнения

$$
d_{4}^{20}=a+b n_{D}^{20}
$$

которые позволяют рассчитать плотности 1 -, 2 -, 3-изомеров $\boldsymbol{H}$-алкинов по данным о показателях преломления для $20^{\circ}$.

\section{ЛИТЕРАТ У РА}

1. Физнко-химические свойства индивидуальных углеводородов. Под ред. проф. В. И. Татевского, М., 1960.

2. Z wolinski, B. J., Wilhoit, R. C., Handbook of Vapor Pressures and Heats of Vaporization of Hydrocarbon and Related Compounds, Texas, 1971.

3. Queignec, R., Wojtkowiak, B., Bull. Soc. Chim. France, 11, 3829 (1970).

4. A s inger, F., Fell, B., St eff a n, G., Chem. Ber., 97, 6, 1555 (1964).

5. Эй зен О., Эльв ельт А., Кудрявцев а Л., Изв. АН ЭССР. Хим. Геол., 20, 4, 287 (1971).

6. Эльвельт А., Ӭй зен О., Кудрявцев а Л,, Изв. АН ЭССР. Хим. Геол,, 21, 1,24 (1972).

7. Michkelson, W. J., Elwelt, A. A., Kudrjawzewa, L. S., Eisen, O. G., Monatsh. Chem., 105, 1379 (1974).

Ннститут химии

Академии наук Эстонской ССР
Поступила в редакцию $10 / \mathrm{V} 1977$ 